\title{
una isla llamada serendipia: definiciones ético pedagógicas en el proyecto
}

\section{filosofar con niñxs.}

\author{
sergio andrade \\ universidad nacional de córdoba, córdoba, argentina \\ orcid id: https:/ / orcid.org/0000-0002-4720-0419
}

resumen

El presente texto plantea, a modo de ensayo, algunas líneas de reflexión y acción relativas a un Proyecto que vincula Filosofía e Infancia, cuya actividad pedagógica e investigativa se desarrolla en la ciudad de Córdoba, Argentina, desde hace más de veinticinco años. Para ello recuperamos una experiencia de talleres con niñxs y adultxs, en un continuo trabajo de reflexión sobre la infancia y el pensar sobre sí mismxs. Tal experiencia se centra en imaginar un espacio y tiempo particular -la convivencia en una isla donde no se encuentran adultxs, y desde allí interrogarse sobre las formas de decisión y participación -de acción políticaque lxs niñxs tienen en los territorios que habitan. Aquí se plantea que la circunstancia de incompletitud respecto a temas como política y sexualidad abarca a todas las situaciones etarias y, por ello, resulta más adecuado dejarnos atravesar por la inquietud, la duda, que aceptar un mundo preconcebido de lugares asignados, donde los problemas encuentran rápida respuesta, y aquello que no se sabe o no se puede ubicar en un casillero es desconocido, ignorado, permanece oculto. Se propone no postular ningún preconcepto relativo a las infancias, pensarlas como hipótesis, que en cada territorio tendrán nombres, cuerpos y pensamientos por (re)conocer. Así también, se asume que la reflexión sobre la práctica de enseñanza reubica a los docentes de filosofía como intelectuales, que dejan las explicaciones universales en sus bolsillos profesorales, que se reinventan al ocuparse de problemas específicos, situados, pequeños descubrimientos que encuentran en sus intercambios con otrxs, de esxs otrxs que, como en el caso de lxs niñxs, hay mucho para aprender. Esa es la tarea ética y política que se desprende de un continuo reflexionar sobre la acción compartida. Bienvenidxs, pues, a la isla donde todo está por decidirse y participarse, la isla de Serendipia.

palabras claves: filosofar; infancias; enseñanza; ética; reflexión.

\section{an island called serendipity: ethical and pedagogical definitions in the "philosophizing with children" project.}

An Island called Serendipity: Ethics in the Philosophy with Children Project.

This text proposes some lines of reflection and action related to a project that links philosophy and childhood, whose pedagogical and investigative activity has been developed in the province of Córdoba, Argentina, for more than twenty-five years. To do this we recover an experience of workshops with children and adults, in a continuous process of reflection on childhood and how children think about themselves. That experience focuses on imagining a particular space and time - living together on an island where adults cannot be found--and from there question the forms of decision making and participation - of political action - that children perform in the territories they inhabit. Here it is proposed that the circumstance of incompleteness regarding issues such as politics and sexuality encompass all age situations and, therefore, it is more appropriate to let ourselves be traversed by restlessness and doubt than to accept a preconceived world in which problems quickly find answers, and what you do not know or cannot be located in a fixed category is unknown, ignored, or remains hidden. We propose to start by not postulating 
una isla llamada serendipia: definiciones ético pedagógicas en el proyecto filosofar con niñxs.

any pre-conceived notions regarding childhoods--thinking of them as hypotheses with unexplored names, bodies and thoughts to get to know. Likewise, it is assumed that reflection on teaching practice relocates philosophy teachers as intellectuals who keep universal explanations in their "professorial pockets," and reinvent themselves by dealing with specific problems, the small discoveries one makes through exchanges with others-those others that, as in the case of children, there is much to learn about and from. This is the ethical and political task that emerges from a continuous reflection on shared action. Welcome, then, to the island where everything is to be decided and participated in, the island of Serendipity.

keywords: philosophize; childhoods; teaching; ethics; reflection.

\section{uma ilha chamada serendipia: definições ético pedagógicas no projeto filosofar com crianças.}

resumo

Este texto propõe, em forma de ensaio, algumas linhas de reflexão e ação relativas a um projeto que vincula Filosofia e Infância, cuja atividade pedagógica e investigativa se desenvolve na cidade de Córdoba, na Argentina, há mais de vinte e cinco anos. Para isso recuperamos uma experiência de ateliês com crianças e adultxs, em um trabalho contínuo de reflexão sobre a infância e o pensar sobre si mesmxs. Tal experiência se centra em imaginar um espaço e tempo particular - a convivência em uma ilha onde não tem adultxs, e a partir daí interroga-se sobre as formas de decisão e participação - de ação política - que as crianças têm nos territórios que habitam. Aqui se sugere que a circunstância de incompletude sobre temas como política e sexualidade abarca a todas as situações etárias e, por isso, torna-se mais adequado deixar-nos atravessar pela inquietude, a dúvida, do que aceitar um mundo preconcebido de lugares demarcados, onde os problemas encontram rápida resposta, e aquilo que não se sabe ou não pode situar em uma categoria fixa é desconhecido, ignorado, permanece oculto. Propomos começar por não colocar quaisquer noções pré-concebidas sobre as infâncias, pensando-as como hipóteses, que em cada território terão nomes, corpos e pensamentos inexplorados a (re)conhecer. Da mesma forma, pressupõe-se que a reflexão sobre a prática docente recoloca os professores de filosofia como intelectuais que guardam as explicações universais em seus "bolsos docentes", que se reinventam ao lidar com problemas específicos, situados, pequenas descobertas que encontram nas trocas com outrxs, aquelxs outrxs, como no caso das crianças, há muito o que aprender. Essa é a tarefa ética e política que surge de uma reflexão contínua sobre a ação compartilhada. Bem-vindxs, então, à ilha onde tudo está para ser decidido e participado, a ilha da Serendipia.

palavras-chave: filosofar; infâncias; docência; ética; reflexão. 
una isla llamada serendipia: definiciones ético pedagógicas en el proyecto filosofar con niñxs.

\title{
hacer lugar a la experiencia, un punto de partida.
}

\begin{abstract}
Lustró su vehículo con una gamuza, pateó cada una de las gomas para comprobar si no les faltaba aire, controló -jtuuut, tuuut!- el sonido de la bocina. Y se dispuso a conocer el mundo que se extendía más allá de su barrio. Puso en marcha el rodado. Mientras partía de la vereda de su casa miró a través del espejito retrovisor las baldosas familiares se alejaban cada vez más y él estaba contento.
\end{abstract}

Bornemann E. (1989) Primera Aventura (fragmento 1)

El relato es el comienzo de una aventura. Crónica en primera persona de Andrés, unx niñx ${ }^{1}$ que a los dos años emprende una expedición en solitario por fuera de su casa, a bordo de su triciclo.

Rápidamente algunxs -adultxs o familarizadxs con el mundo adultxafirmarán a viva voz que es una ficción, que ningún niñx puede salir de su casa solo a tan temprana edad, que su familia debe tener serios problemas o no estar bien constituida para semejante descuido. En cada nueva admonición se alejarán vertiginosamente y en sentido contrario a la vivencia singular de esx niñx.

Sabemos que cada experiencia tiene las dimensiones y palpitaciones de quien la experimenta. Sabemos que las anteriores y siguientes experiencias tienen el sabor de la aventura de Andrés: el valernos por nosotrxs mismxs para echarlas a andar. Aunque para hacerlo hayamos requerido obligatoriamente de otrxs -que nos brindan alimento y lecciones para andar en bici o en triciclo-. Aunque de continuo pretendan dirigir nuestros pasos -sólo- por los senderos señalados.

\footnotetext{
${ }^{1}$ Los discursos y los lenguajes no son actos desinteresados. Cuando se sostiene, reproduce y legitima un discurso de desigualdad, invisibilización, discriminación y estigmatización se ejerce una forma de violencia simbólica. Todo lenguaje construido socialmente incluye, nombra y designa, al tiempo que excluye, niega e invisibiliza a determinadxs sujetxs. Con esa convicción sostenemos el uso de la $X$. Una política de lenguaje inclusivo es eso, un intento de visibilización y asunción de una problemática que vulnera los derechos y las existencias de ciertxs sujetxs. En nuestro caso, lxs niñxs.
} 
una isla llamada serendipia: definiciones ético pedagógicas en el proyecto filosofar con niñxs.

El texto que presentamos es un ejercicio del pensar, un pensar en voz alta respecto a cuestiones sobre las cuales gira la acción de un educador ${ }^{2}$. He de referir a la experiencia de veinticinco años coordinando el Proyecto Filosofar con Niñxs ${ }^{3}$, en un trabajo continuo y sostenido con niñxs y adultxs -familias y docentes-. Un ensayo que se realiza no sólo para hacer memoria o dejar registro de lo realizado, sino con la intención de reformular continuamente lo pensado y realizado, que permita, tal como lo plantea Foucault, un ejercicio sobre uno mismo: "que hay que entender como prueba modificadora de sí mismo en el juego de la verdad y no como apropiación simplificadora con fines de comunicación" (Foucault, 2008: 15).

En tal sentido, las palabras puestas en consideración son una forma de ubicar fuera de sí -o de desubicar, entonces- ciertas ideas asumidas, dudas e inquietudes frutos de la experiencia antes mencionada, reflexiones que surgen de una continua vuelta a pensar las acciones llevadas a cabo.

Se trata de un ejercicio para nada fútil. Es imprescindible volver sobre los pasos emprendidos en la práctica porque rápidamente el hacer dentro o en instituciones se normaliza y naturaliza, como parte del proceso de su institucionalización. Por otra parte, y es una hipótesis de trabajo, una necesidad ética se impone: Advertir, señalar y explicitar los supuestos desde los cuales emprendemos nuestras prácticas educativas. En tal sentido, las decisiones de nuestra acción deberían ser coherentes en términos de definiciones teóricas, epistemológicas, metodológicas y procedimentales.

Dentro de las definiciones teóricas desde las cuales asumimos el vínculo entre filosofía e infancia está la prioridad puesta en la interacción y el conocimiento de unx otrx, otrxs. Otrxs con quienes compartir y repartir saberes y aprendizajes.

\footnotetext{
${ }^{2}$ La noción de educador resulta más fecunda que la de enseñante o formador; estos últimos términos se vinculan a una práctica que se concibe jerárquicamente, una acción de alguien que sabe, que se realiza sobre otrxs sujetxs, ignorantes; la educación, en tanto, debería ser comprendida como una práctica interactiva, donde aprendices y enseñantes no son actores fijos sino intercambiables en el mismo acto de participar de una acción colectiva: la resolución de un problema o la práctica interactiva entre todxs.

${ }^{3}$ Proyecto pedagógico e investigativo que, de manera ininterrumpida y desde sus inicios, construye su teoría y su práctica en instancias con niñxs y adultos -familia y docentes-, desarrolla su acción desde el dispositivo taller, con la intencionalidad de abordar la comunidad educativa -sea en escuelas o en espacios sociocomunitarios, como bibliotecas populares, territorios donde el Proyecto se realiza-.
} 
Particularmente, nos importa encontrarnos con esxs otrxs que históricamente no han sido escuchadxs ni se ha prestado atención a sus voces, se las ha desconsiderado. No se trata simplemente de dar un lugar a la palabra de lxs niñxs como un gesto cortés, o una estrategia pedagógica de atender a las ideas previas. Se trata de reconocer que genuinamente las infancias son portadoras de saberes y experiencias propias.

Otra hipótesis desde la cual pretendemos encontrarnos con las infancias -las de lxs niñxs y las de lxs adultxs-, es considerar que la realidad no es algo dado, sino que se construye. La realidad es una construcción social que se realiza intersubjetivamente.

Así también es necesario considerar a lxs niñxs como sujetxs políticxs. En muchas lecturas y representaciones de las infancias su politicidad es una cualidad en potencia, que se actualizará en el cruce con una instancia legal y de desarrollo evolutivo. De allí que la escuela aparece como la institución con mayor reconocimiento para tutelar este pasaje que recorre toda la escolaridad.

Este imaginario se encuentra interpelado actualmente por el reconocimiento de lxs niñxs como sujetxs de derecho y, por consiguiente, dejan de ser comprendidxs como objetxs de cuidado y protección.

Entonces, lxs niñxs son sujetxs políticxs y a la vez sujetxs sexuados.

Foucault (2008) advierte que la sexualidad infantil, que hasta el Siglo XVII transcurre sin mayores sujeciones, sufre un proceso de negación, ocultamiento que luego se transformará en prácticas médicas y pedagógicas para su formación y encauzamiento -dado que, junto a la prescripción, aparecen formas proscritas de sexualidad-. Así, Foucault (2012) cuestiona la categoría misma de sexualidad:

La sexualidad no debe pensarse como un tipo de hecho natural que el poder trata de mantener controlado, ni como un dominio oscuro que el conocimiento trata de descubrir gradualmente. Es el nombre que puede darse a un constructo histórico.

Constructo histórico que se disemina en tecnologías y prácticas de control y disciplinamiento.

Las infancias son políticas y sexuadas. Sus experiencias de la educación política y de la educación sexual están incompletas. Tan incompletas como está nuestra educación sexual y educación política como adultxs. Porque las 
una isla llamada serendipia: definiciones ético pedagógicas en el proyecto filosofar con niñxs.

experiencias de lo político y la sexualidad no tienen fin, son prácticas que continuamente se rehacen a la luz del entramado social y su conflictividad inherente.

Pensemos sólo las implicancias que en el orden de la sexualidad y la política se pueden plantear a partir de la ley de identidad de género, o las definiciones que devienen de enfatizar la Integralidad de la Educación Sexual ${ }^{4}$. Desde allí se comprende lo que significan en Argentina hoy los movimientos feministas como el Ni Una Menos, donde ambos temas se articulan -como ocurre continuamente en nuestras vidas-.

Sexualidad y política son cuestiones centrales para repensar la infancia y su carácter plural. Buena parte del silencio y el ocultamiento que han sufrido las infancias devienen de una lectura universalista que las niega $u$ omite las diversidades; en imaginarios que sostienen la idea de incompletitud desde la cual instituciones sociales -la familia, la escuela- han construido definiciones teóricas y metodológicas para el trabajo con niñxs. Definiciones que pueden fortalecer esos imaginarios o ponerlos en tensión.

En el trabajo con docentes que emprendemos desde talleres y seminarios, se propician juegos y ejercicios que permiten reconocer las construcciones sociales desde las cuales hemos concebido discursos y prácticas sobre las infancias, la política, la sexualidad ${ }^{5}$. El ejercicio con unx mismx procura reconocer las propias implicaciones dentro de esas construcciones, las incomodidades que nos surgen, interrogarlas, cuestionar la historicidad de la infancia y del binomio sexo género. Así también, frente a la experiencia que venimos teniendo respecto a las acusaciones relativas a la denominada ideología de género es necesario indagar sobre las

\footnotetext{
${ }^{4}$ En Argentina las leyes de Identidad de Género (26.743/2012) y la Ley de Educación Sexual Integral (26.150/2006) significan el reconocimiento y la corporización de las luchas que emprendieron distintas organizaciones de DDHH y Diversidades de Género.

${ }^{5}$ Desde el año 2008 realizamos un Seminario Taller, dentro del Ciclo de Formación Profesional de la Escuela de Ciencias de la Educación. En sus últimas ediciones se validó también como "Seminario interdisciplinario con eje en el currículum" -obligatorio para la carrera del Profesorado en Filosofíade la Escuela de Filosofía, y se abrió a otras carreras (Antropología, Psicología, Comunicación). En ocasiones su temática fue más específica, y se tituló: Políticas de la Infancia, Sexualidad e Instituciones En 2020 se presenta como Seminario Filosofar con Niñxs: aportes y reflexiones de un proyecto dentro y fuera de la escuela, Facultad de Filosofía y Humanidades, Universidad Nacional de Córdoba.
} 
construcciones cristalizadas y el carácter ideológico, construido, de toda noción de sexualidad.

Es relevante subrayar que las instituciones sociales -la escuela, la familia, el club- siempre han enseñado sobre política y sexualidad. Un aporte significativo desde su inclusión en espacios curriculares, o como contenido transversal, refiere a la visibilización de estas enseñanzas que, en muchas ocasiones, se enunciaban -y se enuncian- desde las definiciones particulares de docentes o instituciones que universalizaban, o universalizan, su reflexión moral ${ }^{6}$.

Es preciso comprender que la infancia y su estudio se ha constituido en un campo de discusión, de discursos y prácticas sociales históricas, donde la filosofía participa en su enunciación junto a otras disciplinas y prácticas sociales, como uno de los modos particulares de interrogar(nos) e intervenir en ese campo ${ }^{7}$.

Con relación a los vínculos históricos entre filosofía e infancia, Kohan (2004) rastrea diferentes imágenes de infancia que los filósofos han construido desde Platón -o antes Heráclito- a Lipman, para pensar nuevas tradiciones, nuevas infancias, desde aportes de filósofos como Foucault, Deleuze, Agamben y Rancière.

Kohan ha sido formado en el Programa de Lipman y en nuestro país fue uno de sus principales difusores; sin embargo, realiza importantes críticas a los presupuestos acerca de la infancia que aquel Programa sostiene. En diversas publicaciones tales críticas se profundizan, al tiempo de adquirir ambos, infancia y filosofía, otros contornos, otras dimensiones, nuevos vínculos. Así afirma:

Los filósofos de verdad son como los infantes, no hablan como los adultos, son atópicos, no tienen lugar en la comunidad política, están siempre caminando por los bordes, los contornos, las fronteras entre el adentro y el afuera, no están cómodos haciendo lo que 'hay que hacer' Kohan (2009, p. 6).

\footnotetext{
${ }^{6}$ Resulta curioso cómo respecto a los juicios morales (y estéticos) surge un razonamiento o, más bien, una intuición de aspecto cartesiano, que supone acuerdos semejantes al buen sentido o la razón, que se dirime en un (supuesto y aceptado) uso correcto: Las almas más grandes son capaces de los mayores vicios, como de las mayores virtudes; y los que andan muy despacio pueden llegar mucho más lejos, si van siempre por el camino recto, que los que corren, pero se apartan de él (Descartes, 2014) Queda pendiente para nosotrxs, no para Descartes- qué es virtud o vicio, qué es rectitud, y quién/es y de qué manera se establece/n.

${ }^{7}$ El concepto de campo es definido por Bourdieu como un conjunto de relaciones de fuerza entre agentes o instituciones, en la lucha por formas específicas de dominio y monopolio de un tipo de capital eficiente en él (Gutiérrez, 1997).
} 
una isla llamada serendipia: definiciones ético pedagógicas en el proyecto filosofar con niñxs.

Junto a nuestras hipótesis de trabajo antes mencionadas, sostenemos que las definiciones metodológicas deben ser coherentes con la intencionalidad de proveer de herramientas que permitan la "toma de la palabra" por parte de lxs niñxs, esa acción política en términos de Rancière.

A través del dispositivo taller8, en todos nuestros juegos y ejercicios procuramos habilitar espacios de interrogación propia para la búsqueda de respuestas individuales y colectivas, siempre provisorias, o renovar y profundizar los interrogantes.

Filosofar es la propuesta, acción que requiere de un ejercicio de la escucha, la interrogación mutua, la inquietud. Porque más allá de las enunciaciones de discursos teóricos, de la política educativa o las formulaciones jurídicas, lxs niñxs siguen sin ser reconocidxs como sujetxs de derecho en las prácticas de decisión y participación dentro de las instituciones que habitan. Tomar la palabra, como ocurría en el ágora griego, es una condición -isegoría- para que aquella voz acallada comience a decir lo suyo.

De esto se trata la enseñanza, o una enseñanza que enfatiza el lugar de un otrx en el intercambio de saberes y experiencias, desde el reconocimiento del carácter performativo, fundamentalmente político, de las propuestas de enseñanza.

A continuación, recuperamos una experiencia a partir del dispositivo citado.

\title{
encuentro en la isla
}

\begin{abstract}
No se escapaba de su casa, no. No tenía ningún motivo para hacerlo: Andrés quería mucho y era muy querido. Simplemente, ese domingo se había despertado con ganas de viajar y el impulso de las ganas le había hecho olvidar de que lo correcto era avisarles a sus padres, pedirles permiso.
\end{abstract}

Bornemann E. (1989) Primera Aventura (fragmento 2)

\footnotetext{
${ }^{8}$ No contamos con espacio suficiente para desarrollar los sentidos asignados al concepto dispositivo. Asumimos que las definiciones metodológicas no son meros procedimientos instrumentales. Que en ellas se juegan decisiones éticas, políticas, epistemológicas. Cf. Andrade S. (2016, p-245): Toda práctica de enseñanza, todo dispositivo pedagógico presupone una definición política respecto a los sujetos que se vinculan en pos de un determinado aprendizaje, ciertas definiciones de lo real, al tiempo que producen subjetividades.
} 
La experiencia que recuperamos surge de asumir las expectativas que encontramos en las instituciones que nos demandan en nuestro hacer como filósofxs. Asumimos las demandas, al tiempo de resignificarlas.

En las escuelas y espacios sociocomunitarios, más allá de un mayor o menor nivel de inquietud, se nos solicita atender a las interacciones, el orden disciplinario o las pautas de convivencia -preocupación que se manifiesta como un tema que les excede-.

Detrás de este requerimiento se encuentra un supuesto recurrente respecto a la filosofía como rectora respecto al orden moral, que puede determinar o discernir lo que se debe hacer. Junto a ello, pareciera que se persigue el sostenimiento de un régimen moral del mismo modo, con la misma fijeza, que se perciben en las reglas que se construyen respecto a la naturaleza.

Uno de los caminos para encontrar aquello que las infancias pueden enseñarnos, su novedad, surge al generar instancias donde lxs niñxs piensan y analizan sus propias experiencias.

Así, por ejemplo, y luego de un trabajo fuerte respecto a la confianza en los intercambios que suceden en los talleres, es posible que lxs niñxs indaguen sobre sus lugares en la escuela, cómo se construyen como sujetxs alumnxs, qué instancias de decisión y participación están previstas en ese espacio, y qué otras podrían demandar9.

Dar lugar a la pregunta sobre la escuela permite comprender que entrar en esa institución es entrar en una orden de lo obligatorio y ese orden obligatorio es construido por quienes hacen escuela.

Es cierto que no podemos vivir sin sociedad, que somos partícipes de ella, y que las normas son necesarias para la vida en común. Sin embargo, el mundo adultx no registra que lxs niñxs tengan algo para decir, para agregar o distinguir en los espacios que los regulan. Respecto a las normas, pareciera que ellas sólo pueden funcionar desde un marco exterior a ellxs, establecido por lxs mayores de edad.

\footnotetext{
${ }_{9}$ Andrade S. (2005)
} 
una isla llamada serendipia: definiciones ético pedagógicas en el proyecto filosofar con niñxs.

Esta concepción tutelar tropieza con el paradigma que afirma a las infancias como sujetxs de derechos. Así, en talleres con docentes advertimos las dificultades en la construcción de pautas de convivencia. Por una parte, se reconoce como ausencia la casi nula aceptación de la palabra de lxs niñxs para proponer reglas que no sean una simple regulación de sus márgenes de acción, o un decálogo de sanciones por lo común prohibitivas. Junto a ello, lxs adultxs no son puestxs en regla, como lxs niñxs. Lxs niñxs deben solicitar permiso para tomar la palabra, para moverse, para salir de la sala; lxs adultxs, en cambio, suelen realizan todas estas acciones sin realizar ninguna aclaración previa o posterior.

Frente a esta lectura -que como toda generalidad no da cuenta de las situaciones singulares que escapan a un planteo algo esquemático-, podría interrogarse: cómo enseñar filosofía y que esa enseñanza no sea un adoctrinamiento, qué se enseña cuando se busca acercar la filosofía a la infancia y la infancia a la filosofía, de modos fructíferos ${ }^{10}$.

Tal vez podríamos apelar a Rancière/Jacotot: es posible enseñar desde la ignorancia, enseñar lo que se ignora ${ }^{11}$. Y cómo esto será posible: a través del juego en los talleres, jugar a (dis)poner(se) en situación, encontrarnos en problemáticas para resolver -sea desde un plano racional o en acciones de disputa, confrontación, solidaridad con otrxs-. Resoluciones que no necesariamente llegan a consensos o a una conclusión, que pueden despertar nuevas inquietudes. Generar espacios y tiempos de experiencias, de eso se trata.

Bien, tanto rodeo para llegar a una isla.

El encuentro entre filosofía e infancia bien puede ser explicado por la palabra serendipia. Afirman que serendipia es un descubrimiento o un hallazgo afortunado, valioso, inesperado, generalmente accidental, casual o por destino, o cuando se está buscando una cosa distinta a la que se encuentra. Los talleres producen serendipia, producen lo inesperado.

\footnotetext{
${ }^{10}$ Esta discusión, este intercambio productivo de múltiples implicaciones, se encuentra en los textos de Kohan antes citados.

${ }^{11}$ Cf. Rancière J. (2007)
} 
Ahora bien, ese encuentro con lo inesperado tiene que ser paradójicamente esperado, planeado, producido, como ya planteamos, tiene que darse -disponersede un lugar y un tiempo para que ese encuentro sea posible ${ }^{12}$.

Entendemos que no hay temas que se puedan excluir o no se puedan contemplar, discutir, conjeturar, imaginar e interrogar con niñxs -además, si se escucha con atención, ellxs traerán sus preguntas antes de sopesar si la cuestión es o no conveniente-.

Así, asociar la muerte al miedo, por ejemplo, es una impronta de adultxs. Refiero al miedo; la tristeza por la pérdida de un ser querido -un familiar, una planta o una mascota- es inevitable, más allá de la situación etaria. Respecto a los temores de lxs mayores, recuerdo que una vez unx niñx no quería mirar al cielo, que era lo que lxs otrxs hacíamos, porque allí estaban sus abuelxs, según le habían contado. No habría que olvidar que detrás de las preguntas, hay un guión, una proto-teoría, respecto de aquello que lxs niñxs se interrogan, y un principio de respuesta que deciden, que decidimos, cotejar con otrxs -se trate de niñxs o adultxs-.

Una de las experiencias de juego que más impresión causa en lxs niñxs -y la palabra es la más adecuada, la más plástica, porque se impone desde los sentidossucede, ha sucedido, cuando trabajamos El Juego de la Isla. El mismo es una recreación y reinvención de una propuesta de Edwards y Mercer (1988).

Nuestro juego consiste en jugar con la imaginación.

La primera reacción infantil frente a esta invitación es de enojo, y tildan de aburrido un juego que aún no conocen. Jugar con la imaginación es un desafío para estos tiempos hiper mediatizados por tecnologías vinculadas a la informática. Empero, aquí apelamos a sus propias experiencias: ¿Qué hacen cuando tienen que

\footnotetext{
$12 \mathrm{Al}$ respecto, cf. Cerletti A. (2020). En la estrechez de este texto no podemos desarrollar los puntos de encuentro y divergencia acerca de una didáctica aleatoria de la filosofía, a partir de la construcción de subjetividades que se ponen en juego en situaciones de enseñanza, entre enseñantes y aprendices en el filosofar, los intercambios dialécticos, los márgenes de plan y azar que tiene una propuesta como la que presentamos. Ahora bien, El juego de la Isla, que incluye un número indefinido de talleres, con diversas actividades -realizar un recorrido desde la imaginación por el espacio, distribuir grupos para pensar colectivamente tareas necesarias en la isla, dibujar esas tareas, discutir la convivencia sin adultxs, entre otras acciones que se nutren continuamente de interrogantes propixs y colectivxs, refieren a una serie de ingredientes, un abanico de recursos y actividades, un itinerario de posibles que se corporizan en forma particular en cada grupo de trabajo. Esas son formas de pensar lo inesperado. Como andar por el territorio de Serendipia, que no tiene un mapa determinado, pero siempre tiene forma de isla.
} 
una isla llamada serendipia: definiciones ético pedagógicas en el proyecto filosofar con niñxs.

acompañar a lxs mayores en esas tareas tediosas como ir a un banco, esperar en una sala que se llama así, en una terminal antes de realizar un viaje? Allí pueden buscar objetos que están por ahí, a su alcance, pueden transformar la silla o el lápiz en una nave espacial. La imaginación no requiere de muchas cosas, sólo denle una oportunidad.

Entonces imaginamos que unx grupx de niñxs, como lxs chicxs de la sala, realizan un viaje en barco. Imaginamos un viaje a una isla de acuerdo a las posibilidades que este juego imaginario permite: así, al llegar a la isla pueden deambular por un patio o una sala ${ }^{13}$. Mientras caminamos, cada unx por donde desee explorar, vamos pensando qué cosas podemos encontrar en ella: objetos abandonados, vegetación, animales...

Hay una condición innegociable: La Isla está desierta. No hay ningún habitante. Entonces vamos imaginando su geografía; si tiene montañas, volcanes, árboles, si es verano o hace frío. Mientras vamos caminando, al paso que se nos ocurra, y señalamos las especies con las que tropezamos -animales salvajes, otros miedosos o tímidos-, la ínsula imaginaria va cobrando cuerpo, adquiriendo forma real.

En un momento descubrimos algo curioso e inquietante: mientras lxs chicxs hacían la recorrida, por razones extrañas o desconocidas el barco se vuelve sin ellxs $\mathrm{y}$, por lo menos hasta que tengan otras noticias de su regreso, tendrán que resolver qué hacer solxs, sin adultxs.

La primera reacción suele ser de alegría. Gritan, cantan: Qué más quisieran lxs chicxs que estar solxs. Sin nadie que les mande qué hacer, sin alguien que los rete, ni nada.

Pero en breve aparecen otras preocupaciones. Va a caer la noche, también empiezan a sentir ruidos en la panza y eso indudablemente es hambre. A continuación, descubren que hay mucho por hacer y no pueden todxs hacer todo. $Y$

\footnotetext{
${ }^{13}$ En alguna experiencia puntual pudimos jugar en un patio con árboles y otros objetos que se encontraban allí y lxs chicxs pudieron corporizar la idea, construir realmente sus chozas, o sus balsas, en forma de maquetas o cosas parecidas. Empero, tal como asumimos, con la imaginación es suficiente para hacer del aula una isla y fantasear acerca de todo lo que allí puede aparecer.
} 
se viene la noche. Tienen que protegerse, porque recuerdan que había animales peligrosos como los que observaron en su andar.

Se hace imperiosa una organización: conformar grupos para cada tarea. Distribuir las distintas actividades necesarias, entre ellas el cuidado y la protección de todxs; la búsqueda de alimentos; la cocina; la construcción de un lugar para protegerse y dormir; y hasta la construcción de una embarcación para poder irse de la Isla. Cada grupx se organiza para la tarea que les toca y realizan dibujos, planos, discuten resoluciones colectivas.

A la brevedad, o más tarde con los intercambios, aparecen los conflictos. Ahí se les interroga: ¿Cómo resuelven, por ejemplo, si unx no realiza la tarea que le corresponde; o come más de lo previsto para cada unx, o no trabaja? Ahí recordamos, si hace falta, que no hay adultxs y que deben resolver los pleitos solxs.

Las primeras soluciones son extremas: quien no cumple su tarea suele tener como destino ser devorado por los tiburones. Esa solución pronto será puesta en tensión: y si quien no cumple con lo que tiene que hacer fueras vos, ¿te gustaría esa solución?

Entonces aparecen otro tipo de sanciones y con ellas surge la necesidad de reglar la convivencia.

El juego puede dispararse hacia distintos horizontes: ahondar en la problemática de la convivencia y el sentido o los sentidos que pueden tener para lxs convivientes. enfatizando que no hay autoridades externas, otros árbitrxs que dictaminen qué hacer. También suele servir para corporizar los lugares del juego y la imaginación en la escuela, los roles asignados y los estereotipos de género que se asumen en la división de las actividades y al interior de cada grupo. Se puede comparar el vivir en una isla y vivir en otros espacios reglados como la escuela, la familia, el club, entre otros temas.

Como caminos alternativos en el andar por la isla, luego de varios talleres en este juego, se interroga a los chicxs qué cosas y a quienes llegarán a extrañar si tienen que pasar bastante tiempo varadxs en esa situación. 
una isla llamada serendipia: definiciones ético pedagógicas en el proyecto filosofar con niñxs.

En sus inventarios aparecen recurrentemente dibujos animados, la playstation, una mascota, hermanxs, amigxs, quien nos cuida y hasta las familias, lxs maestrxs.

Luego, les proponemos que escriban una carta que reúna estas manifestaciones de sus sentimientos, que será puesta en una botellita para ser arrojada al mar.

Estos textos suelen ser leídos, previo consentimiento de lxs chicxs a sus familias en un taller donde se comparte la experiencia. Un taller donde lxs familiares juegan a ir solxs a una isla, las consecuencias de quedarse allí y tener que convivir sin lxs niñxs. Resulta interesante observar que los modos de resolución del juego por parte de niñxs y adultxs no son muy diferentes.

Finalmente, luego de una larga aventura imaginativa -de una imaginación además construida en forma colectiva- aparece un barco que los rescata y pueden regresar a sus vidas.

Lxs chicxs señalan que es un juego que les gusta muchísimo y año tras año solicitan volver a la isla. Aun cuando nuestras preocupaciones transiten otros temas.

\title{
pensar (otrxs) lugares para lxs filósofxs y la enseñanza
}

\begin{abstract}
Aceleró Ya estaba en territorio desconocido. No había visto antes esas vidrieras, ni aquellas chimeneas, ni esas bocacalles, ni a aquel señor, que lo miró con cierta inquietud cuando Andrés pasó a su lado ¿Se habrá dado cuenta de que aún no tenía registro de conductor? Mejor no averiguarlo. Por las dudas, Andrés imprimió más velocidad a su vehículo y se perdió en el agitado mediodía.
\end{abstract}

Bornemann (1989) Primera Aventura (fragmento 3)

Las prácticas educativas de lxs docentes son interpeladas como prácticas políticas en dos sentidos, por lo menos: en discursos y acciones, por lo dicho, lo he hecho, junto a lo omitido, lo negado. Lxs docentes son sujetxs políticxs porque, como todo ciudadano actúan y establecen vínculos con otrxs; ahora bien, también participan en la educación política de sus estudiantes -aunque no de modo excluyente,- a través de muchas acciones. Lxs docentes no sólo enseñan de política 
a través de sus discursos, enseñan respecto a la participación y la decisión de lxs otrxs, de los silencios que propicia, las emociones y lxs cuerpxs que se contactan o alejan.

Durante mucho tiempo, cierta construcción de sentido común sostenía, palabras más o menos, que las acciones de lxs docentes debían mantenerse en la neutralidad. Afirmamos que es una idea peligrosa y de improbable realización. Las decisiones tanto desde el orden metodológico como de contenido -en verdad, lo metodológico es contenido- determinan la propuesta de acción y su ejecución. Acciones que nunca son neutrales -y de allí la peligrosidad de quien postula esto.

Para pensar los lugares de la pregunta en la práctica filosófica, habría que cuestionarse sobre las formas de interrogar/se que legitiman u obturan alternativas. En el caso de la enseñanza de la filosofía, ¿tal práctica permite preguntar o exige interrogatorios relativos a voces o problemas ajenos?

El encuentro entre filosofía e infancia será más rico desde una práctica que habilite a una pedagogía de la pregunta -en términos de Freire-, que permita una interrogación sobre unx mismx y las prácticas que se suceden junto a otrxs, sin la obsesión por buscar necesariamente respuestas, dar lugar a la duda y a la inquietud, a la sospecha.

Para ubicarse en las preguntas de las múltiples infancias, una estrategia entre tantas posibles, es acudir al arte, fundamentalmente a las propuestas que abren a la polisemia. La apertura hacia múltiples significados, nos liberan de pretender discursos moralizantes y unívocos. Hasta aquí, fui acompañando la aventura de Andrés. Hay que reconocer que la aventura tiene las dimensiones de la singularidad de la experiencia.

Es necesario buscar la legibilidad y visibilización de otras infancias: como aquella que promete la historia de unx niñx aborigen, para interrogarnos sobre las culturas nativas; los relatos que provienen de infancias diversas $u$ otras que se dibujan en tiempos de dictadura, entre otrxs ${ }^{14}$.

\footnotetext{
14 Nos referimos entre muchos posibles, y centrándonos aquí solo en la literatura como una de las formas expresivas, a: Assadourian (1999) Tiquilis, La aventura de un niño aborigen. Córdoba: Graziani; Shock (2017) Crianzas, Historias para crecer en toda la diversidad. Buenos Aires: Ed. Muchas Nueces; Skarmeta (2007) La composición. Caracas: Ed. Ekaré.
} 
una isla llamada serendipia: definiciones ético pedagógicas en el proyecto filosofar con niñxs.

Ahora bien, ¿qué más puede pretender la filosofía como enseñanza? Foucault no hace referencia directa en su obra a la enseñanza, aunque mucho de lo que se ha publicado en este tiempo recupera sus conferencias y clases. Sí escribió con frecuencia en torno a la labor del intelectual y, podríamos incorporar al filósofo en este plan:

Durante mucho tiempo, el llamado intelectual de «izquierdas» tomó la palabra arrogándose el derecho de hablar como maestro de la verdad y la justicia. Le escuchábamos, o se hacía escuchar, como representante de lo universal. Ser intelectual, era ser un poco la conciencia de todos (Foucault, 1994, p.156)

Tal lectura de la intelectualidad era presentada para destruir esa concepción, anacrónica, imposible de realizar, su voluntad de verdad, la universalidad y su aspiración a la representación de otrxs. Frente a ella, Foucault plantea una tarea localizada, específica para reconocer problemas a los cuales estudiar:

A través del pequeño gesto que consiste en desplazar la mirada, el intelectual vuelve visible lo que es invisible, hace aparecer lo que está cerca, tan inmediato, tan íntimamente ligado a nosotros mismos que no lo vemos. (Foucault, 1994, p.109)

Para avanzar sobre terreno aún fangoso, en el trabajo pendiente sobre unx mismx, quisiera retomar brevemente la problemática de la sexualidad, en torno al género: "El problema del género es que prescribe cómo tenemos que ser, en vez de reconocer cómo somos realmente" (Adichie, 2018: 41)

Entonces planteo, en voz alta, y desde la singularidad desde la que he podido hablar, pensar, decir, actuar; desde un lugar de privilegio: hombre, blanco, CIS, que se ha formado y transita en un escenario heteronormativo, binario, patriarcal, capitalista; que hace uso de una situación de privilegio, más allá de todas las excusas, prerrogativas o discursos que pueda (de)enunciar respecto a las situaciones de desigualdad que sufren quienes no están contempladxs en tan estricto sistema categorial.

Podemos, puedo reconocer, ponerme en pie y subrayar -como ya he señalado- que se trata de categorías construidas cultural e históricamente, que como tales pueden, y deben, modificarse:

La cultura no hace a la gente. La gente hace la cultura. Si es verdad que no forma parte de nuestra cultura el hecho de que las mujeres sean seres humanos de pleno derecho, entonces podemos y debemos cambiar nuestra cultura. (Adichie, 2018: 53) 
No se trata, como advierte Foucault, de subirse a un pedestal y señalar el camino a seguir. Al contrario, se imponen los gestos mínimos, un silencio mayúsculo de quienes hemos vivido presxs de los privilegios. Desde allí acompañar la marcha, junto a la denuncia de sus voces y cuerpxs, de quienes han sido históricamente silenciadxs: mujeres, diversidades, disidencias, infancias, entre otrxs. Y escuchar como una bella canción, como un poema o una flecha dirigiéndose al centro de este injusto mundo, esta declaración:

Hoy me gustaría pedir que empecemos a soñar con un plan para un mundo distinto. Un mundo más justo. Un mundo de hombres y mujeres más felices y más honestos consigo mismos. Y esta es la forma de empezar: tenemos que criar a nuestras hijas de otra forma. Y también a nuestros hijos (Adichie, 2018, p.32).

También a nuestrxs hijxs, repito. $\mathrm{Y}$ agrego como un mantra: a nuestrxs predecesorxs, a nuestrxs descendencias, nuestrxs disidencias y sus decisiones. Y quisiera no olvidarme de nadie. Mientras sigo preguntándome, para acercarme más a los aprendizajes pendientes que se suceden por las calles.

\section{palabras que recapitulan un recorrido -para preparar una nueva aventura-.}

En los últimos cincuenta años se ha procurado indagar acerca de vínculos entre filosofía e infancia. A tales relaciones se ha incorporado la preocupación por la educación, en términos generales, y por la enseñanza como cuestión específica. De tal modo, uno de los espacios relevantes en la discusión acerca de la enseñanza de la filosofía proviene de experiencias como las aquí citadas. La total alteridad de lxs destinatarixs de las prácticas filosóficas radicaliza la necesidad de interrogarse acerca de los intercambios posibles, las subjetividades que se construyen, las formas metodológicas para que tales interacciones sean fructíferas.

Sin embargo, hay mucho pendiente en la discusión sobre los presupuestos epistemológicos de las propuestas más reconocidas, como el Programa Filosofía para Niños, en redefiniciones teóricas relativas a la infancia, desde un reconocimiento de la misma como un campo de conocimientos que la comprenda en plural o en la multiplicidad de sus manifestaciones.

Al respecto, vienen en auxilio expresiones aclaratorias: 
una isla llamada serendipia: definiciones ético pedagógicas en el proyecto filosofar con niñxs.

La infancia es también infancias y la filosofía es, antes que otra cosa, filosofías. Los filósofos también nos ayudan a tener cuidado. Lo múltiplo no es lo plural, la diferencia no es la diversidad. En todo caso, la infancia y la filosofía son múltiples y viven de la diferencia o, para decirlo con palabras más del presente, de la diferencia de las diferencias. Como tal, habitan en múltiples inicios. Aquí sólo sugerimos algunos entre ellos: arbitrarios, contingentes, anecdóticos, como también lo son infancia y filosofía (Kohan, 2009: 7).

Acerca de esas diversidades, Filosofar con Niñxs asume sus indagaciones en territorios.

Otras discusiones que sostenemos se sitúan en la tensión entre las propuestas que vinculan filosofía e infancia y que entienden una disciplina -la filosofíapensada para unxs sujetxs particulares -lxs niñxs- y quienes refieren a una actividad o una praxis que se pone en juego con lxs niñxs. Controversia que se ubica en los términos del "para" o el "con". Al respecto, nos interesa discutir con un reciente texto de Alarcón Castillo (2020), quien establece una línea de continuidad entre una y otra propuesta de enseñanza de la filosofía y la infancia, desestimando experiencias que han surgido por fuera de la matriz del Programa de M. Lipman y A. Sharp, y sus presupuestos; reconocer que es posible y se han desarrollado experiencias y proyectos por fuera de ese paradigma dominante no implica sólo un dato estadístico, brinda elementos de análisis y de comparación respecto a esta problemática. Así también, hipotetizamos que tal discusión renueva, refunda y da una respuesta particular a un viejo debate en el campo de la enseñanza de la filosofía, que retoma el dictum kantiano respecto al enseñar filosofía y aprender a filosofar (Rabossi, 2004), y a las alternativas de lxs sujetxs que se construyen desde esas experiencias.

Al mismo tiempo de asumir que, en una continua tensión entre la conservación de lo que se sabe, y se construye como campo académico (Goodson, 1992), y el interés por irrumpir en el orden establecido, desde una subjetividad -no pensada como tal-:

...el filosofar es una construcción compleja en la que cada filósofo, o aprendiz de filósofo, incide singularmente en aquello que hay de la filosofía. Podemos decir que, en sentido estricto, de eso se trata el pensar: intervenir de una manera original en los saberes establecidos de un campo. Quien filosofa, pensará los problemas de su mundo en, desde o contra una filosofía (Cerletti A., p.52). 
Volvemos al inicio de este texto, retomamos el relato y un viaje en triciclo.

El cuento recupera, también, una modalidad de trabajo que se sostiene en procesos más de orden inductivo, en experiencias propias y colectivas situadas, antes que en proposiciones y presupuestos deductivos, que predeterminan una infancia y un destino de la enseñanza filosófica. Son decisiones que configuran definiciones de la filosofía y sus modos de hacer con otrxs.

En este texto no hemos hecho más que eso ${ }^{15}$. Hemos compartido, a partir de la recuperación de experiencias, ciertos presupuestos teórico metodológicos que orientan un Proyecto. Un Proyecto que desde sus inicios se ha propuesto indagar las relaciones posibles entre filosofía e infancias con lxs distintxs sujetxs que intervienen e intercambian en su construcción subjetiva. Investigar en y con las infancias no para construirlos en objeto de estudio sino para reflexionar y repensar colectivamente las formas que inventamos, propiciamos, reflexionamos y hacemos infancias.

Para ello hace falta imaginación, afilar interrogantes, sensaciones y sentires, asumir pensamientos y deseos de aventurarse a vagar por mundos desconocidos sin la mano o la voz de unx adultx. Que no es otra cosa que lo que experiencian las infancias.

\section{bibliografía}

Adichie CH. N. (2018) Todos deberíamos ser feministas.Ciudad Autónoma de Buenos Aires: Literatura Random House.

Alarcon Castillo, V. (2020) Filosofía y niños: ¿para o con?, en childhood \& philosophy, rio de janeiro, v. 16, jul. 2020, pp. 01- 29.

Andrade, S. (2016) "El dispositivo taller como práctica política para filosofar con niños"(p. 245- 252), en Encuentros de lo posible y lo imposible: Actas del I Congreso Latinoamericano de Filosofías e Infancias / Julio Fernando Acosta Muñoz [et al.]; Comp. María Inés Bello [et al.] Ciudad Autónoma de Buenos Aires: Grupo El Pensadero. Libro digital, ISBN 978- 987-46298-0-7.

Andrade, S. (2015) “Filosofar con Niños Un proyecto para habitar e inquietar el pensamiento". Pérez J, Álvarez J; Guerra Araya C. Hacer filosofía con niños y niñas. Entre educación y filosofía . Valparaíso: Instituto de Filosofía, Universidad de Valparaíso.

Andrade, S. ( ) "La niñez como sujeto de derecho. Una aproximación desde el Proyecto Filosofar con Niñxs", en I Jornadas en Derechos Humanos, organizadas desde el

\footnotetext{
${ }^{15}$ Este texto sólo puede construirse desde el sostenimiento de las hipótesis que atraviesan el Proyecto.
} 
una isla llamada serendipia: definiciones ético pedagógicas en el proyecto filosofar con niñxs.

Programa de Derechos Humanos de la Facultad de Filosofía y Humanidades de la UNC.

Andrade, S. (2005) "Buscando contenidos propios en la filosofía con niños: La construcción de la subjetividad escolar", en Childhood \& Philosophy; a journal of the international council of philosophical inquiry with children, Julio 2005.

Bornemann E. (1989) El niño envuelto (Cuentos sin cuento para chicos de 8 a 13 años), Buenos Aires: Ediciones Orión.

Cerletti A. (2020) Ensayos para una Didáctica Filosófica.Núcleo de Estudos de Filosofias e Infâncias (NEFI/UERJ), Rio de Janeiro.

Edwards D., MERCER N. (1988) El conocimiento compartido: El desarrollo de la comprensión en el aula, Barcelona, Paidós.

Foucault, M. (2008) Historia de la sexualidad 1. La voluntad de saber. México: Siglo XXI.

Foucault, M. (2008) Historia de la sexualidad 2. El uso de los placeres. Buenos Aires: Siglo XXI.

Foucault, M. (1994) Dits et Écrits, vol. III, Paris, Gallimard,

Freire, P. Faúndez A. (2004) Por una pedagogía de la pregunta. Buenos Aires: Siglo XXI.

Goodson I. (1995) Historia del currículum. La construcción social de las disciplinas escolares. Edic. Pomares- Corredor. Barcelona.

Kohan, W. (2004) Infancia entre Educación y Filosofía. Buenos Aires: Laertes.

Kohan, W. (2009) Infancia y filosofía. México: Progreso.

Ranciere J. (2007) El maestro ignorante, Cinco lecciones sobre la emancipación intelectual, Buenos Aires: Libros del Zorzal.

recibido en: 07.11.2020

aprobado en: 02.04.2021 